OPEN ACCESS

Edited by:

Nour Eissa,

University of Manitoba, Canada

Reviewed by:

Eva Sierra,

University of Las Palmas de Gran

Canaria, Spain

Mikko Juhani Nikinmaa,

University of Turku, Finland

${ }^{*}$ Correspondence:

Xia-Yun Jiang

jiangxy@shou.edu.cn

Shu-Ming Zou

smzou@shou.edu.cn

Specialty section: This article was submitted to

Aquatic Physiology,

a section of the journa

Frontiers in Physiology

Received: 01 December 2017

Accepted: 21 February 2018

Published: 06 March 2018

Citation:

Sun $Y$, Guo $H-H$, Guo D-D, Jiang $X-Y$ and Zou S-M (2018) Divergence of Genes Encoding CITED1 and CITED2 in Blunt Snout Bream (Megalobrama amblycephala) and Their Transcriptional Responses to Hypoxia. Front. Physiol. 9:186 doi: 10.3389/fphys.2018.00186

\section{Divergence of Genes Encoding CITED1 and CITED2 in Blunt Snout Bream (Megalobrama amblycephala) and Their Transcriptional Responses to Hypoxia}

\author{
Yuan Sun, Hong-Hong Guo, Dan-Dan Guo, Xia-Yun Jiang * and Shu-Ming Zou* \\ Key Laboratory of Freshwater Aquatic Genetic Resources, Ministry of Agriculture, Genetics and Breeding Center for Blunt \\ Snout Bream, Shanghai Ocean University, Shanghai, China
}

The proteins CITED belong to a family of non-DNA-binding transcriptional co-regulators involved in the regulation of various transcriptional responses. Previous studies suggest that members of CITED family may function in response to hypoxia in mammals. however, the molecular and functional information on CITED genes in aquaculture fish is unclear. Here, we characterized and examined the transcriptional patterns of CITED1 and CITED2 genes in the hypoxia-sensitive blunt snout bream (Megalobrama amblycephala). Blunt snout bream CITED1 and CITED2 genes shared a relatively low sequence identity of 45\%. CITED1 and CITED2 mRNAs were widely transcribed in adult tissues. During embryogenesis, CITED1 mRNA was significantly transcribed at 4, 24, 28, 40, and 44 hpf, whereas CITED2 mRNA levels fluctuated from the zygote to 44 hpf larval stage. Whole-mount in situ hybridization demonstrated that CITED1 and CITED2 mRNAs were detected in the brain at $12 \mathrm{hpf}$, brain and gut at $24 \mathrm{hpf}$, and brain at $36 \mathrm{hpf}$. In addition, low expression of CITED1 mRNA was detected in the tailbud at $24 \mathrm{hpf}$. The results of acute hypoxia experiment showed that CITED1 and CITED2 mRNAs were markedly upregulated in the kidney and downregulated in the liver, brain, gill, and heart under hypoxia. Embryos in hypoxic conditions at different developmental stages showed a significant increase in mRNA levels of CITED1 and CITED2. These results provide a new insight into the divergence of CITED1 and CITED2 genes and their transcriptional responses to hypoxia.

Keywords: blunt snout bream, CITED1, CITED2, hypoxia, transcriptional responses

\section{INTRODUCTION}

The proteins CITED, cAMP-responsive element-binding protein (CBP)/p300-interacting transactivator with glutamic acid (E) and aspartic acid (D)-rich C-terminal domain, are involved in the modulation of a variety of cellular and developmental processes and responses to environmental stimuli at the transcriptional level in mammals (Dunwoodie et al., 1998; Yahata et al., 2001). 
To date, four different homologs (CITED1-4) have been reported in vertebrates (Bhattacharya et al., 1999). CITED1, formally known as MSG1, was first isolated in 1996 from murine melanoma B16-F1 cells (Shioda et al., 1996) and mapped to chromosome Xq13.1 in humans (Fenner et al., 1998). CITED2, originally called as MRG1 (MSG1-related gene 1) shares transcription-activating CR1 (14 amino acid residues) and CR2 ( $\sim 50$ amino acid residues) domains with CITED1 (Shioda et al., 1997). Hypoxic conditions lead to the formation of a DNA-binding complex containing both hypoxia-inducible factor 1 (HIF-1) alpha and CBP/p300. Hence, CBP/p300-HIF complexes participate in the induction of hypoxia-responsive genes (Bracken et al., 2003; Kinoshita et al., 2004; Shen et al., 2010). Members of CITED family may bind to CBP/p300 with a strong affinity and negatively regulate HIF-1 transactivation (Bhattacharya et al., 1999; Ng et al., 2010).

Although CITED family plays diverse roles in mammals (Dunwoodie et al., 1998; Schlange et al., 2000; Bamforth et al., 2001; Yahata et al., 2001, 2002), their functions related to oxygen regulation are questionable. Recent studies in teleost fish have highlighted their transcriptional activities responsible to alleviate the effect of hypoxia and fine-tune a number of signaling pathways coping with oxygen change (Ng et al., 2003, 2009, 2010; van den Beucken et al., 2007; Yoon et al., 2011). To date, CITED genes have been identified in zebrafish and grass carp genome (Ng et al., 2003, 2009, 2010; Thisse et al., 2004). CITED genes in grass carp may be transcribed in a negative feedback loop to regulate HIF-1 transactivation in response to hypoxia stress (Ng et al., 2009, 2010). Although the information on the embryonic expression of CITED1 in zebrafish is lacking, CITED2 mRNAs are transcribed in the brain and a part of cephalic nervous system using whole-mount in situ hybridization (Thisse et al., 2004). In addition, our previous transcriptome results of blunt snout bream have shown that both CITED1 and CITED2 genes are associated with the expression of hypoxia by transcriptome analysis (Li et al., 2015). Thus, further studies are essential to determine the transcriptional responses of CITED1 and CITED2 at the molecular level in important aquaculture fish species.

As a principal herbivorous species in freshwater fish polyculture systems, blunt snout bream (Megalobrama amblycephala) is widely favored as a delicacy in China. The production output of blunt snout bream was more than 0.7 million tons in 2015 (FBMA., 2016). Temperature fluctuations, low photosynthetic activity, and low or stagnant water flow may cause hypoxia in fish culture ponds (Karim et al., 2003; Martínez et al., 2011). A short period $(<2 \mathrm{~h})$ of hypoxia (less than $0.5 \mathrm{mg} / \mathrm{L}$ ) at room temperature may be lethal (Shen et al., 2010; Tian et al., 2014; Li et al., 2015). Blunt snout bream, an extremely hypoxia-sensitive fish, has a relatively high critical oxygen tension of $0.9 \mathrm{mg} / \mathrm{L}$ at $10^{\circ} \mathrm{C}$, at which it loses its equilibrium ( $\mathrm{LOE}_{\text {crit }}$ ) (Wu et al., 2017). Based on the differential expression patterns of CITED1 and CITED12 genes during transcriptome analysis of blunt snout bream under hypoxia condition (GenBank SRP050593) (Li et al., 2015), we analyzed the molecular and spatiotemporal expression patterns as well as the transcriptional responses of these genes to acute hypoxia.

\section{MATERIALS AND METHODS}

\section{Experimental Fish Culture and Treatment}

All experiments were conducted following the guidelines approved by the Shanghai Ocean University Committee on the Use and Care of Animals. Blunt snout bream was obtained from the Bream Genetics and Breeding Center of Shanghai Ocean University, Shanghai, China. Fertilized eggs were generated by artificial insemination. Fertilized eggs (100-200) were plated in each Petri dish ( $15 \mathrm{~cm}$ in diameter). Egg fertilization and embryo development was carried out at room temperature $\left(\sim 20^{\circ} \mathrm{C}\right)$. During embryogenesis, water in the Petri dish was replaced every $4 \mathrm{~h}$ with well-aerated water to maintain the normal value of dissolved oxygen (DO) of $7.0 \pm 0.5 \mathrm{mg} / \mathrm{L}$ (Ouyang et al., 2001). DO was monitored continuously using a dissolved oxygen meter (YSI Pro-ODO, Germany). Embryos were stored every $4 \mathrm{~h}$ after fertilization $(0 \sim 44 \mathrm{hpf})$ by immersing in RNA Store (Tiangen, Shanghai, China) and kept in $4^{\circ} \mathrm{C}$ overnight and then $-80^{\circ} \mathrm{C}$ until used. Five adult blunt snout bream were euthanized by immersion in MS-222 (Sigma, St. Louis, MO, USA). The weight of 2-year-old adult blunt snout bream was 1,000 $\mathrm{g}$ according to the experimental requirements. Tissues (brain, gill, eyes, muscle, skin, heart, liver, spleen, kidney, intestine, and gonad) were rapidly dissected, frozen in liquid nitrogen and stored at $-80^{\circ} \mathrm{C}$ until use.

\section{Hypoxia Treatments of Embryos}

Embryos were subjected to hypoxia as recently reported (Zhang et al., 2017). During embryogenesis, water in the Petri dish was

TABLE 1 | Primer sequences used in this study.

\begin{tabular}{|c|c|}
\hline Primers name & Primer sequence $\left(5^{\prime}-3^{\prime}\right)$ \\
\hline CITED1-RT-F1 & САСТСТСССТССТGСАСТАС \\
\hline CITED1-RT-R1 & GCGACATCAGAACTTCCTCATC \\
\hline CITED2-RT-F1 & CCGCAGCAGCAGCATTAT \\
\hline CITED2-RT-R1 & CCAAGCCCATTTCTATCA \\
\hline CITED1-3RACE-O & CGGCACAGACACCTGGGAT \\
\hline CITED1-3RACE-I & GATGAGGAAGTTCTGATGTCGC \\
\hline CITED1-5RACE-O & GCAGCAGGACTGGAAACA \\
\hline CITED1-5RACE-I & AGGGCTCGTCTTGCCTGAAC \\
\hline CITED2-3RACE-O & GTCTGGGGTTCCTCTGCCTGG \\
\hline CITED2-3RACE-I & TTATTGACGAGGAGGTCTTGATG \\
\hline CITED2-5RACE-O & CTGGGATTGTCAGTTACTIITGCT \\
\hline CITED2-5RACE-I & GTGATTTGCGTTTACATTCCСTCCC \\
\hline CITED1-in situ-F & CCAGCACCTCATAGCCTCC \\
\hline CITED1-in situ-R & ACGGCTTCTCAAGGGAATCTCA \\
\hline CITED2-in situ-F & TTGACGAGGAGGTCTTGATGT \\
\hline CITED2-in situ-R & TGTTCTGTGGGTTATCGTTTG \\
\hline CITED1-q RT-F & CGACTTCGGATCTGTTCTTG \\
\hline CITED1-q RT-R & GTGCAGGAGGGAGAGAGAGT \\
\hline CITED2-q RT-F & AGACGCGTGTGTTTATTCGT \\
\hline CITED2-q RT-R & AATGTTGTTGCTGTGGAAGC \\
\hline $18 \mathrm{~S}-\mathrm{q} R \mathrm{RT}-\mathrm{F}$ & ACCGCAGCTAGGAATAATGG \\
\hline 18S-q RT-R & GGTCGGAACTACGACGGTAT \\
\hline
\end{tabular}


replaced with well-aerated slow-flowing water to maintain the normal value of dissolved oxygen (DO) of $7.0 \pm 0.5 \mathrm{mg} / \mathrm{L}$ at room temperature $\left(\sim 20^{\circ} \mathrm{C}\right)$. Blunt snout bream embryos at different developmental stages $(2,8,14,20$, and $26 \mathrm{hpf})$ were exposed to severe hypoxic DO conditions $(3.5 \pm 0.5 \mathrm{mg} / \mathrm{L}$ ) for $6 \mathrm{~h}$ (see Zhang et al., 2017). Oxygen was depleted by bubbling water with

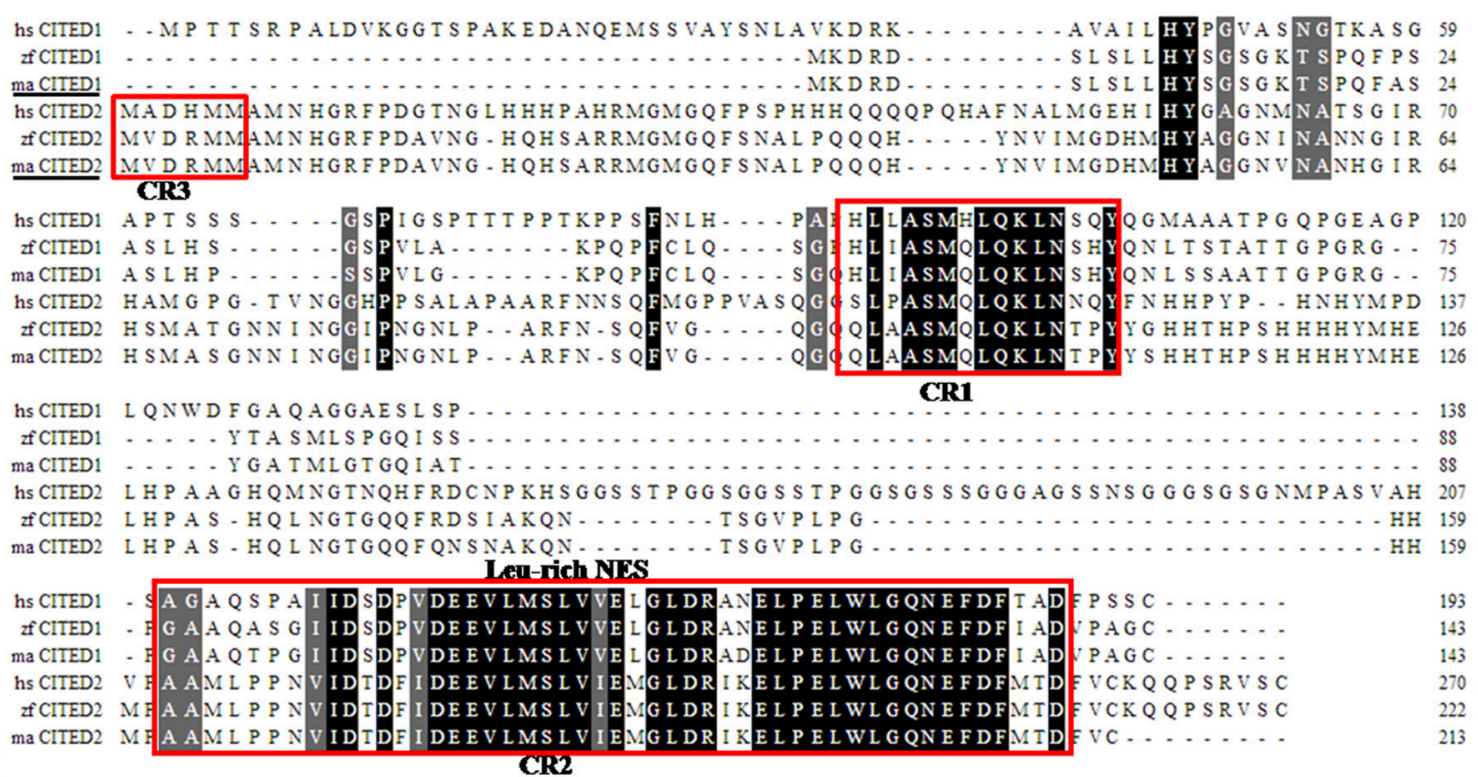

FIGURE 1 | Alignment of deduced blunt snout bream (ma) CITED1 and-2 amino acid sequences with zebrafish (zf) and human (hs) homologs. The CITED domain (CR1, CR2, CR3) is indicated by red boxes, and the CITED signature (Leu-rich NES) is indicated by red frame.
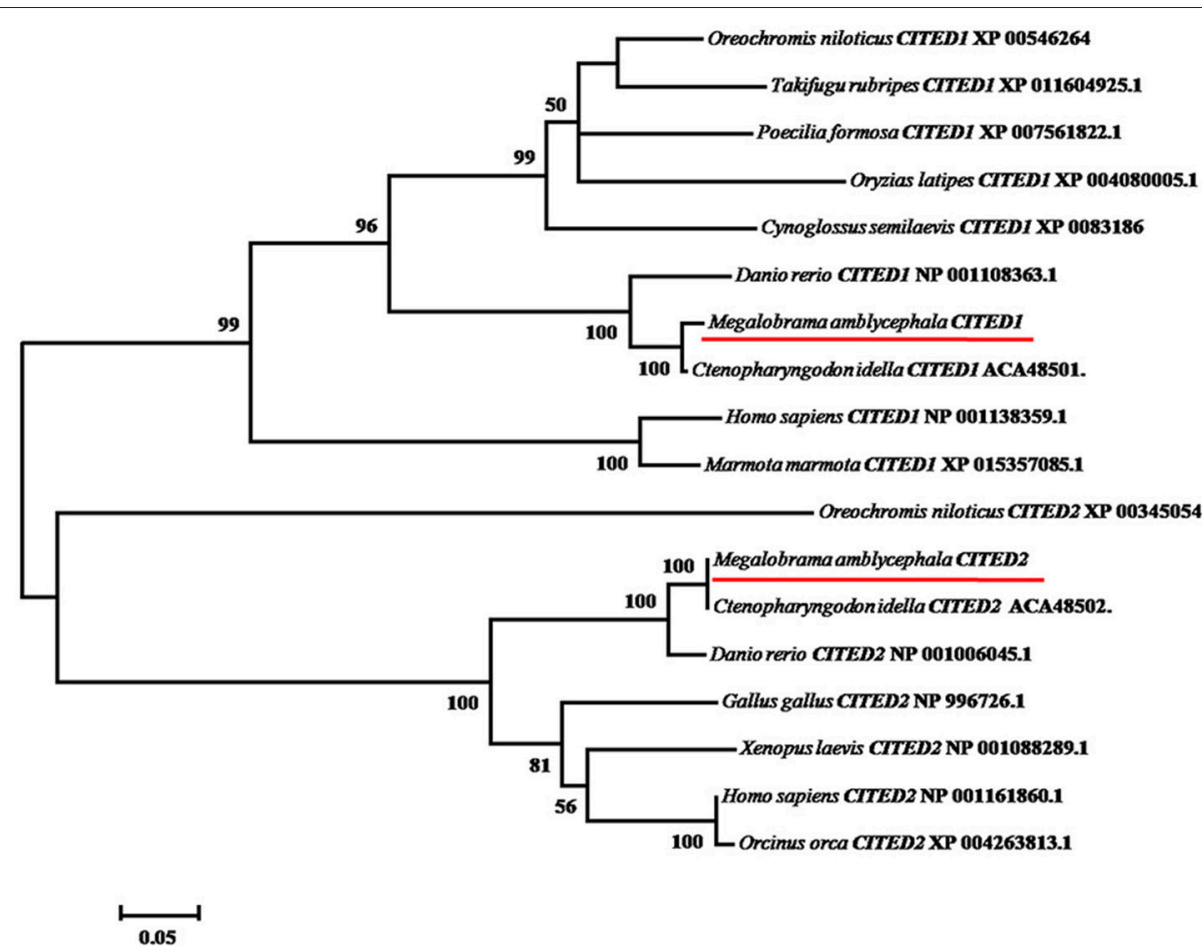

FIGURE 2 | Phylogenetic analysis of vertebrate CITED1 and-2. Accession numbers of sequences retrieved from GenBank and European Molecular Biology Laboratory are shown. The tree was constructed by the neighbor-joining method using MEGA 6.06 software. The bootstrap values derived from 1,000 replications are shown. Objective gene has been highlighted in red line. 
nitrogen gas (Zhang et al., 2003). The embryos at similar stages under normoxic DO conditions were used as controls. After each exposure period, 20 embryos were submersed in RNA store (Tiangen, Shanghai, China), maintained at $4^{\circ} \mathrm{C}$ overnight, and stored at $-80^{\circ} \mathrm{C}$ until total RNA isolation. Each experiment was performed in triplicates.

\section{Hypoxia Treatments on Juvenile Fish}

For the juvenile fish treatment, 30 juvenile blunt snout bream $(150 \sim 160 \mathrm{~g}$ each) were randomly transferred into three $50 \mathrm{~L}$ tanks within a continuous flow system (10 individual per tank). After 1 week of acclimation, two groups were exposed to severe hypoxic $\mathrm{DO}$ conditions $(\mathrm{DO}=1.0 \pm 0.5 \mathrm{mg} / \mathrm{L})$ for $4 \mathrm{~h}$ by nitrogen-filled manipulation and a control group was retained under normoxic DO conditions ( $\mathrm{DO}=7.0 \pm 0.5 \mathrm{mg} / \mathrm{L}$ ) (Guan et al., 2017). Another two parallels were set for the control and experimental groups, respectively. After the exposure period, five fish from each experimental group and the control group were sacrificed. Then DO levels of two hypoxic treatment groups were adjusted to normal levels within $1 \mathrm{~h}$ by bubbling air. The remaining five fish from each recovery treatment and the control group were sampled after $24 \mathrm{~h}$. Tissues were immediately excised, frozen in liquid nitrogen and stored at $-80^{\circ} \mathrm{C}$ until use.
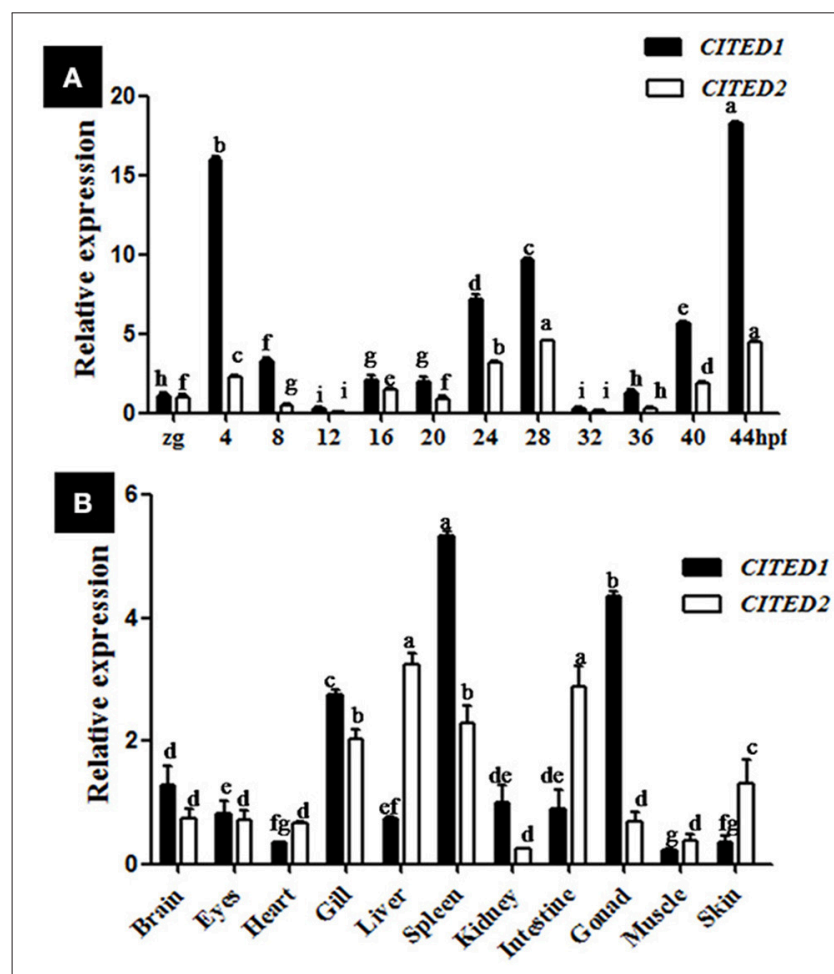

FIGURE 3 | Expression of CITED1/-2 mRNAs during embryogenesis (A) and in adult tissues (B) of blunt snout bream. The relative expression was analyzed by QRT-PCR. The CITED1/-2 copy numbers were normalized to the amount of $18 \mathrm{~S}$ mRNA. The results are given as mean \pm SE for separate samples $(n=5)$. Columns marked with different letters are significantly different $(p<0.01)$. Zg, zygote; hpf, hours post-fertilization.

\section{Molecular Cloning of Blunt Snout Bream CITED1 and CITED2 cDNAs}

Total RNA was isolated from blunt snout bream embryos at 44 hpf using TRIzol reagent (Invitrogen, Carlsbad, CA,USA) and subsequently treated with DNase (Promega, Madison, WI, USA) to remove contaminant genomic DNA. First-strand cDNA was reverse transcribed from the total RNA by using reverse transcriptase M-MLV (TaKaRa, Japan) with oligo-dT primers according to the manufacture's instructions. The primer pairs for CITED1 and CITED2 mRNA were designed based on transcriptome data of blunt snout bream (Li et al., 2015). PCR was performed to amplify partial cDNA fragments of blunt snout bream CITED1 by using the primers CITED1-F and CITED1-R (Table 1). A 315-bp partial PCR fragment of blunt snout bream CITED1 was cloned, sequenced, and used to design nested gene-specific primers for $3^{\prime}$ rapid amplification of cDNA ends (RACE) analysis and 5'RACE analysis (Table $\mathbf{1}$ ). And similar to the above method, a 460-bp partial PCR fragment of blunt snout bream CITED2 was cloned, sequenced, and used to design nested gene-specific primers for $3^{\prime} \mathrm{RACE}$ analysis and $5^{\prime} \mathrm{RACE}$ analysis (Table 1). The $5^{\prime}$ and $3^{\prime}$ ends of CITED1 and CITED2 mRNAs were amplified using the SMART RACE cDNA amplification kit (Clontech, Mountain View, CA, USA). PCR products were gel-purified, ligated into the cloning vector pGEM-T (Promega, Madison, WI, USA), and transformed into Escherichia coli DH5 $\alpha$ competent cells. Positive clones were examined by PCR and direct sequencing.

\section{Sequence and Phylogenetic Analyzes}

The putative sequences of CITED1 and CITED2 protein from different species were compared using the National Center for Biotechnology Information BLASTP search program. Nucleotide sequences of CITED1 and CITED2 were analyzed using BioEdit 7.0.0.1 (Jeon et al., 2014). Alignment of putative amino acid sequences of the CITED1 and CITED2 proteins was performed with Clustal X 1.81 (Thompson et al., 1997). Phylogenetic analysis was performed using coding sequences with the neighbor-joining (NJ) method in MEGA 6.06 (Tamura et al., 2013). Gap sites in the alignment were used for the phylogenetic reconstruction. Reliability of the estimated tree was evaluated using the bootstrap method with 1,000 pseudo-replications.

\section{Whole-Mount in Situ Hybridization}

A 853-bp PCR fragment of blunt snout bream CITED1 amplified by primers CITED1-In situ-F/-R (Table 1) and a 509-bp PCR fragment of CITED2 amplified by primers CITED2-In situ-F/-R (Table 1) were subcloned into the pGEM-T vector (Tiangen, Beijing, China). Each template plasmids was linearized by restriction enzyme digestion, followed by in vitro transcription with SP6 or T7 RNA polymerase to generate the antisense or sense RNA riboprobes, respectively. Fixed embryos were washed briefly in PBS containing 0.1\% Tween-20, transferred to $100 \%$ methanol, and stored at $-20^{\circ} \mathrm{C}$ for a minimum of $24 \mathrm{~h}$. Whole-mount in situ hybridization using digoxigenin (DIG)-labeled RNA riboprobes was performed as reported 
previously (Jiang et al., 2012). Embryos were hybridized with appropriate riboprobes at $60^{\circ} \mathrm{C}$, incubated with antiDIG antibodies conjugated with alkaline phosphatase (AP) and stained with Roche BM Purple AP substrates (Roche, Basel, Switzerland) to produce purple, insoluble precipitates. Embryos were photographed using a Nikon SMZ1500 fluorescence microscope (Tokyo, Japan).

\section{Quantitative Real-Time PCR}

Total RNAs were isolated from embryos at the same developmental stage during embryogenesis or from tissues of blunt snout bream by using the TRIzol reagent (Invitrogen). After DNase treatment, $600 \mathrm{ng}$ total RNA was reversetranscribed to single-strand cDNA using a Prime Script RT reagent kit (TaKaRa, Japan) according to the manufacturer's instructions. Quantitative real-time PCR (qPCR) was carried out on a CFX96 Touch $^{\text {TM }}$ real-time PCR Detection System (BioRad, Hercules, CA, USA) according to the manufacturer's instructions. The hypoxia stable $18 \mathrm{~S}$ gene was amplified by 18S-qRT-F/-R (Table 1) and served as the internal reference. Primer pairs were CITED1-qRT-F/-R and CITED2-qRT-F/-R (Table 1). The qPCR was performed using SYBR Green Premix Ex Taq (TaKaRa, Japan). The program for qRT-PCR was $95^{\circ} \mathrm{C}$ for $30 \mathrm{~s}$ and 40 cycles of amplification at $95^{\circ} \mathrm{C}$ for $5 \mathrm{~s}$, $59.5^{\circ} \mathrm{C}$ for $20 \mathrm{~s}$, and $72^{\circ} \mathrm{C}$ for $15 \mathrm{~s}$. The molecular number of a particular gene transcript was calculated based on the standard curve and normalized to the 18S mRNA level. Each experiment was repeated in triplicate. The expression level of different genes was analyzed using the comparative CT method (2- $2^{-\Delta C T}$ method) (Livak and Schmittgen, 2001) after the PCR program.

\section{Statistical Analysis}

Data from the qRT-PCR are expressed as means \pm SE. Differences among groups were analyzed with a one-way ANOVA followed by Fisher' s post-hoc tests or unpaired $t$-tests. Significance was accepted at the level of $p<0.01$.

\section{RESULTS}

\section{Identification of CITED1 and CITED2 cDNAs in Blunt Snout Bream}

The full-length cDNA sequences of both CITED1 (GenBank Acc. No. KX913945) and CITED2 (GenBank Acc. No. KX913946) genes were obtained in blunt snout bream. CITED1 cDNA was $1,459 \mathrm{bp}$ in length and comprised a $249 \mathrm{bp} 5^{\prime}$-untranslated region (5'-UTR), a 432 bp open reading frame (ORF) encoding 143 amino acid residues and a 778 bp $3^{\prime}$-UTR including a poly-(A)

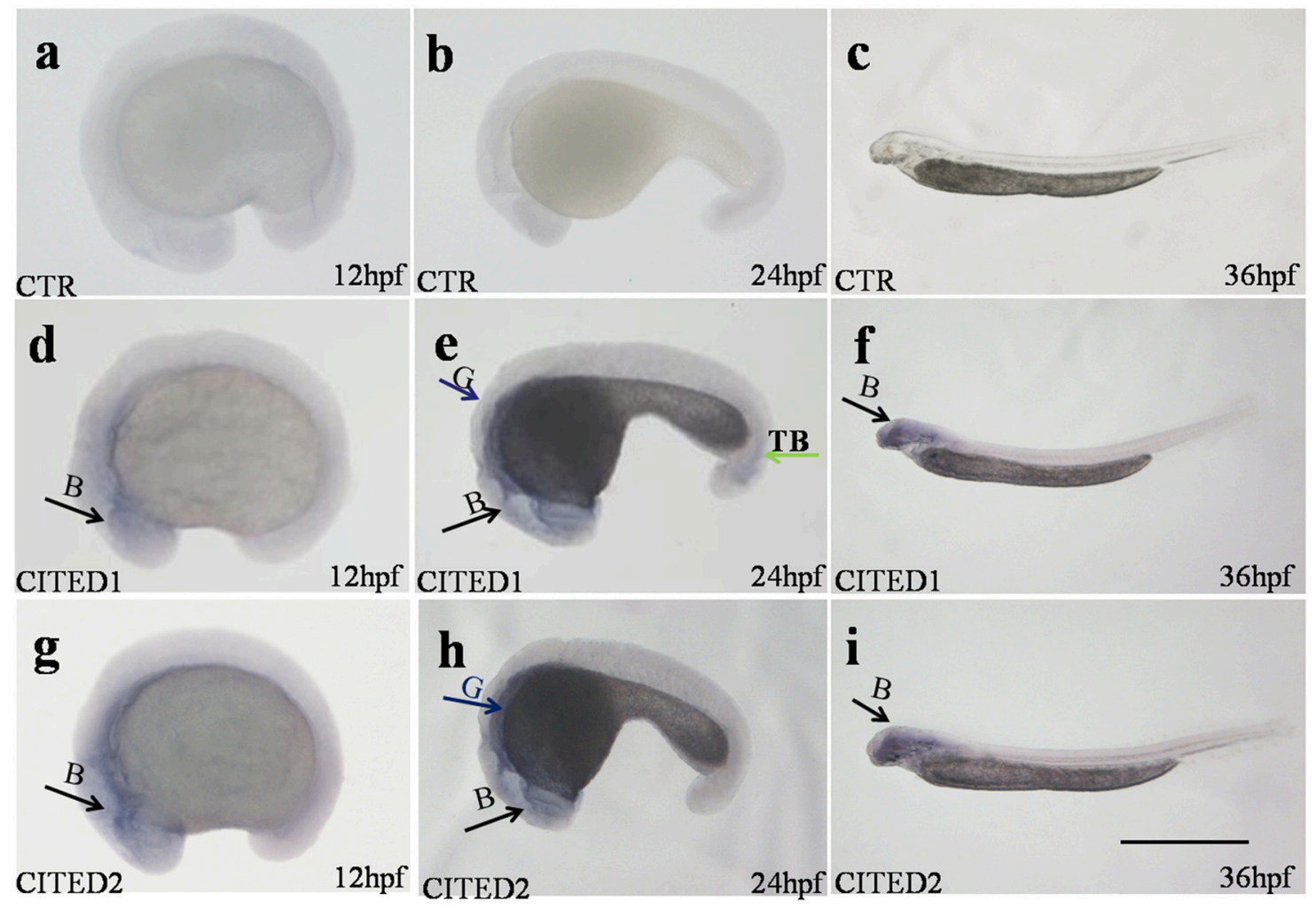

FIGURE 4 | Whole-mount embryo in situ hybridization analysis at different embryonic stages of CITED1/-2 mRNA of blunt snout bream. CITED1 antisense probe (D-F), CITED2 antisense probe (G-I), and CITED1 or -2 sense probe (A-C) were used. All embryos are viewed laterally with the head to the left. B, brain; G, gut; TB, tail bud. Scale bar $=500 \mu \mathrm{m}$. 
tail (Figure 1). The CITED2 cDNA was 1,530 bp in length, containing a 291 bp 5'-UTR, 642 bp ORF encoding 213 amino acid residues and 598 bp $3^{\prime}$-UTR.

Multiple alignments suggest that both CITED1 and CITED2 peptides from blunt snout bream were predicted to consist of CR1 and CR2 domains displaying a leucine-rich nuclear-export signal (Leu-rich NES), as observed in other species. (Figure 1). In addition, CITED2 peptide displayed CR3 domain (Figure 1). Pairwise comparison showed that the mature peptides CITED1 and CITED2 had low sequence identities (45\%). Sequence analysis showed that CITED1 protein of blunt snout bream shared high sequence identity with CITED1 from grass carp (94\%) and zebrafish (83\%). Moreover, CITED2 protein of blunt snout bream shared high sequence identity with CITED2 from grass carp (95\%) and zebrafish (93\%). The phylogenetic tree demonstrated that CITED1 and CITED2 of blunt snout bream are well clustered with their orthologs in other species (Figure 2).

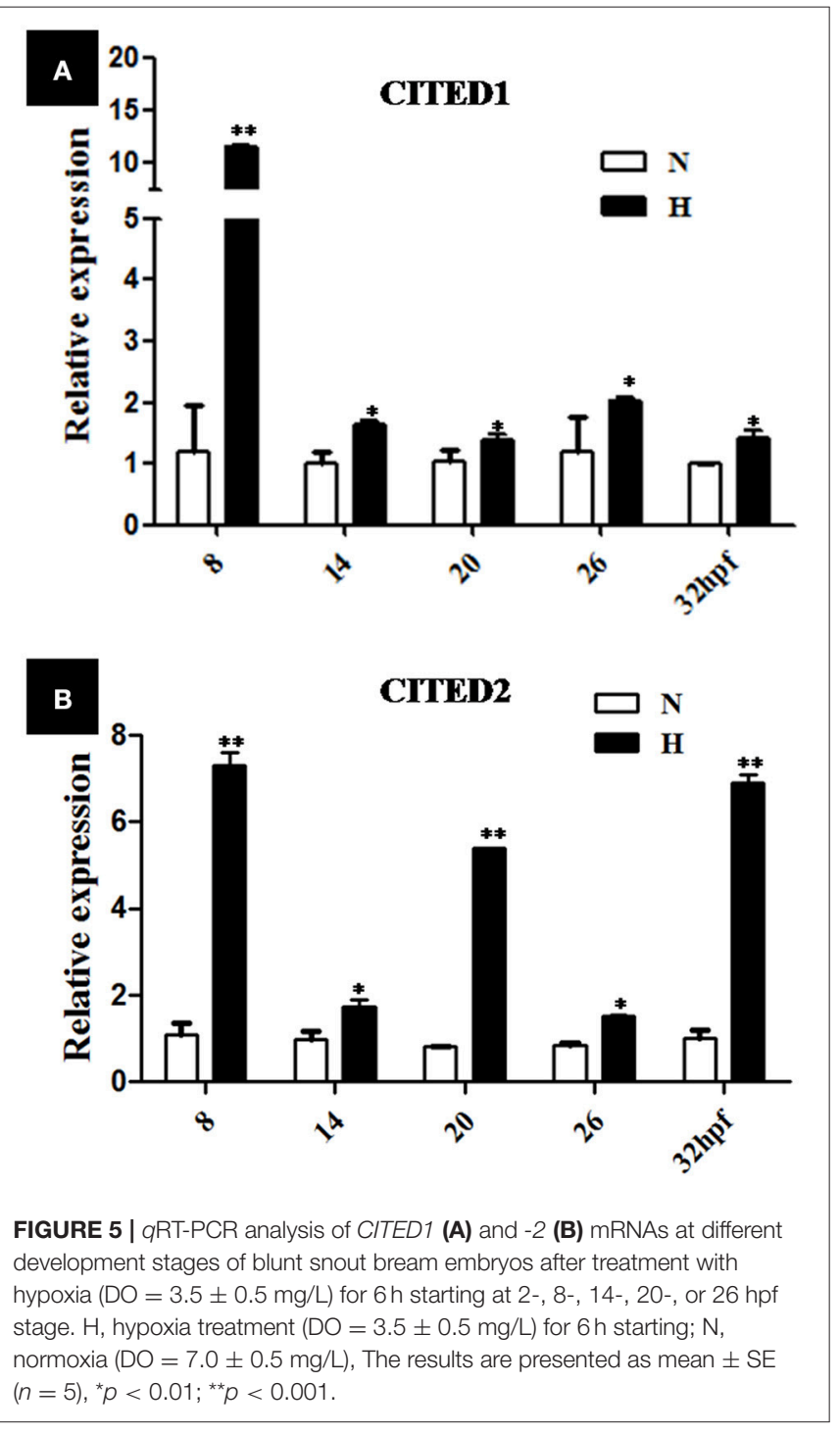

\section{Transcriptional Patterns in Embryo and Adult Tissues of CITED1 and CITED2 mRNAs}

Both CITED1 and CITED2 mRNAs were maternally deposited, as their transcripts were detected in the zygote. Blunt snout bream CITED1 mRNA was significantly expressed $(p<0.01)$ at $4,24,28,40$, and $44 \mathrm{hpf}$ (Figure 3A). On the other hand, CITED2 mRNA fluctuated from the zygote to $44 \mathrm{hpf}$ larvae (Figure 3A). Both CITED1 and CITED2 mRNAs were detected in multiple adult tissues in blunt snout bream. CITED1 mRNA was highly expressed in the spleen, gonad, and gill and moderately expressed in the brain, kidney, intestine, eyes, and liver. The expression of CITED1 mRNA was relatively low in the muscle, heart, and skin (Figure 3B). CITED2 mRNA was highly expressed in the liver, intestine, spleen, and gill, while its expression was moderate in the skin, brain, eyes, heart, and gonad. Kidney and muscle tissues showed relatively low level of CITED2 mRNA expression (Figure 3B). CITED1 or CITED2 sense probe (Figures $4 \mathrm{~A}-\mathrm{C}$ ), CITED1 antisense probe (Figures 4D-F) and CITED2 antisense probe (Figures 4G-I) were detected in the whole-mount embryo during the in situ hybridization analysis of embryos at different developmental stages. Whole-mount in situ hybridization results showed that both CITED1 and CITED2 mRNAs were detected in the brain at $12 \mathrm{hpf}$ (Figures 4D,G), brain and gut at $24 \mathrm{hpf}$ (Figures 4E,H), and brain at $36 \mathrm{hpf}$ (Figures 4F,I). In addition, weak expression of CITED1 mRNA was detected in the tailbud at $24 \mathrm{hpf}$ (Figure 4E).

\section{Transcriptional Responses of CITED1 and CITED2 to Hypoxia During Embryogenesis}

Various stages of the embryos $(2,8,14,20$, and $26 \mathrm{hpf})$ were subjected to hypoxic treatment $(\mathrm{DO}=3.5 \pm 0.5 \mathrm{mg} / \mathrm{L})$ for $6 \mathrm{~h}$. Embryos from the normoxia group served as controls for every time point. As indicated by $q \mathrm{PCR}$ analysis, the relative transcriptional level of CITED1 and CITED2 significantly $(p<0.01)$ increased after $6 \mathrm{~h}$ hypoxia treatment at different stages as compared with the controls (Figures 5A,B). In particular, the relative transcriptional level of CITED1 at 8 hpf and CITED2 at 8, 20, and $32 \mathrm{hpf}$ was 10, 7, 5, and 7 times higher, respectively than that observed in the controls at the same developmental stage after $6 \mathrm{~h}$ hypoxia treatment (Figures 5A,B).

In comparison with the control embryos at $26 \mathrm{hpf}$ (Figures 6A,C), those under hypoxia showed an obvious increase in levels of both CITED1 and CITED2 in the brain. In addition, the transcriptional regions of both genes in the brain were expanded under hypoxia (Figures 6B,D). Additional CITED1 signals were detected in the yolk sac and trunk mesoderm tissue of hypoxia-treated embryos (Figure 6B). Moreover, mRNA levels of both CITED1 and CITED2 at $56 \mathrm{hpf}$ embryos after $30 \mathrm{~h}$ recovery (Figures 6F,H) were similar to those observed for controls from same development stage (Figures 6E,G). An increase in the mRNA expression of CITED1 and CITED2 was observed in $32 \mathrm{hpf}$ embryos after $6 \mathrm{~h}$ hypoxia treatment (Figures 6J,L) as compared with 
the control at the same stage (Figures 6I,K); the expression level was restored in $62 \mathrm{hpf}$ embryos after $30 \mathrm{~h}$ recovery (Figures 6M-P).

\section{Transcriptional Responses of CITED1 and CITED2 in Juvenile Fish Under Hypoxia Stress}

To determine whether blunt snout bream CITED1 and CITED2 genes were involved in the transcriptional response to hypoxia, juvenile fish were exposed to normoxia ( $\mathrm{DO}=7.0 \pm 0.5$ $\mathrm{mg} / \mathrm{L})$ and hypoxia $(\mathrm{DO}=1.0 \pm 0.5 \mathrm{mg} / \mathrm{L})$ conditions. The relative expression of CITED1 and CITED2 mRNAs in the liver, brain, gill, heart, and kidney during hypoxic treatment were estimated by qPCR (Figure 7). The experimental data suggest that CITED1 and CITED2 shared a similar responsive mode at the transcriptional level. Although CITED1 and CITED2 mRNA were significantly $(p<0.01)$ upregulated in the kidney (Figure 7E), a significant $(p<0.001)$ downregulation in the expression of these mRNAs was observed in the liver, brain, gill, and heart (Figures 7A-D) during hypoxic stress. After a recovery stage of $24 \mathrm{~h}$, both CITED1 and CITED2 mRNA expressions returned to the normal level in various tissues (Figure 7).

\section{DISCUSSION}

In this study, we isolated and characterized two CITED1 and CITED2 genes in blunt snout bream, a commercially hypoxia-sensitive aquaculture fish species in China. Blunt snout bream CITED1 and CITED2 mature peptides are very similar to other teleost CITED1 and CITED2 peptides ( 90\% identity). However, the overall sequence identity between CITED1 and CITED2 mature peptides was only 45\%. These observations are in line with those previously reported in grass carp (Ng et al., 2003). Each CITED1 and CITED2 gene clustered with its mammalian homologous gene, suggesting that these are not derived from fish-specific genome duplication (Taylor et al., 2003).

Both CITED1 and CITED2 mature peptides of blunt snout bream comprised two highly conserved CR1 and CR2 domains with a highly conserved signature motif. Domain CR3 is absent in CITED1 peptide (Dunwoodie et al., 1998; Bhattacharya et al., 1999). CR2 domain displaying a leucine-rich nuclear-export signal is the characteristic domain of the CITED protein family. It is known that CR2 domain is crucial, especially during the function of CITED1 and CITED2 as transcription activators (Shioda et al., 1997). Through CR2 domain, CITED 1 and CITED2 compete with HIF-1 for binding to $\mathrm{CH} 1$ domain of
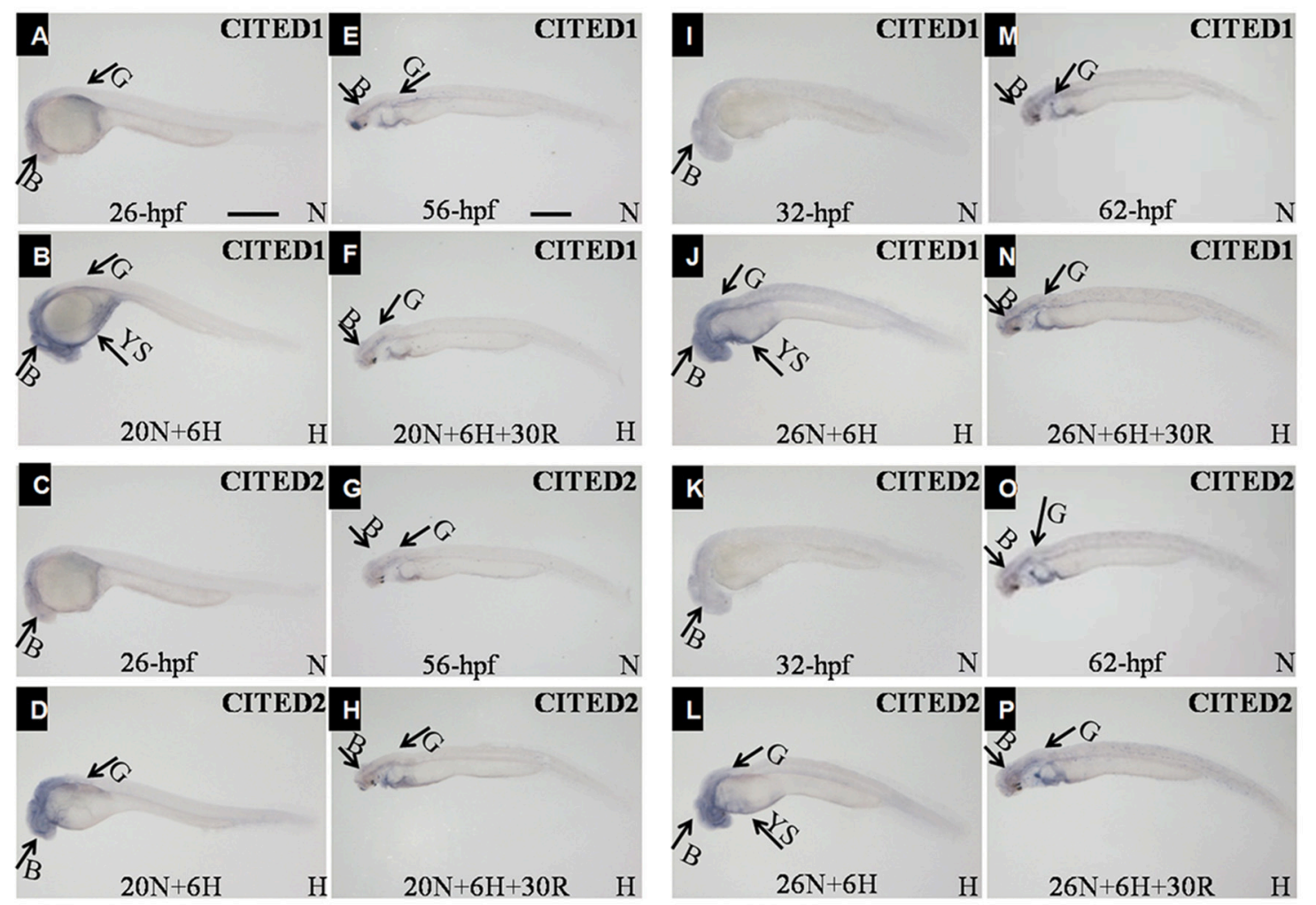

FIGURE 6 | Whole-mount embryo in situ hybridization analysis using the C/TED1 (A,B,E,F,I,J,M,N) or -2 (C,D,G,H,K,L,O,P) antisense probe. All embryos are viewed laterally with the head to the left. B, brain; G, gut; TB, tail bud; YS, yolk sac; $H$, hypoxia (DO = $3.5 \pm 0.5 \mathrm{mg} / \mathrm{L}) ; \mathrm{N}, \mathrm{normoxia}(\mathrm{DO}=7.0 \pm 0.5 \mathrm{mg} / \mathrm{L}) ; \mathrm{Scale}$ bar $=500 \mu \mathrm{m}$. The embryos at (B, D) experienced hypoxia treatment for $6 \mathrm{~h}$ starting at $20 \mathrm{hpf}$. The embryos at (F,H) embryos are $30 \mathrm{~h}$ recovery for the embryos at (B,D). The embryos at (J,L) experienced hypoxia treatment for $6 \mathrm{~h}$ starting at $26 \mathrm{hpf}$. The embryos at (N,P) embryos are $30 \mathrm{~h}$ recovery for the embryos at $\mathbf{( J , L )}$. 
CBP/p300 (Bhattacharya et al., 1999; Fox et al., 2004; Ng et al., 2010). The conservation CR2 domain may imply structural and functional similarities between CITED proteins during evolution.

During embryogenesis, both CITED1 and CITED2 mRNAs of blunt snout bream showed fluctuated expression from the zygote to $44 \mathrm{hpf}$ larval stage. They were mainly transcribed in the brain at different embryonic development stages. Our results were consistent with the observation reported in zebrafish, wherein strong CITED2 transcriptional signals were detected in the brain and some parts of cephalic nervous system at similar embryonic stages (Thisse et al., 2004). Moreover, gene knockout studies have shown that CITED2 is required for normal embryonic development. Neural crest defects, exencephaly and other developmental defects were found in mice lacking CITED2 (Bamforth et al., 2001). Furthermore, the expression of CITED1 were detected at the brain in adult and developing murine (Gerstner and Landry, 2007). Despite the lack of transcriptional or translational information on CITED1 and CITED2 in spatial embryo of other fish species, our results suggest that duplicated CITED1 and CITED2 genes in blunt snout bream may play overlapping biological roles in the development of cephalic nervous system at transcriptional level.

Oxygen is undoubtedly of significant importance for life but may be influenced by changing circumstances. Cells of fish and other animals can maintain oxygen homeostasis as a resistance mechanism to hypoxic stress by modulating the expression level of related genes (Yachie et al., 1999; Semenza, 2001; Giaccia et al., 2004; Nilsson and Ostlund-Nilsson, 2004). Studies have shown that the transcription of a series of related genes may be upregulated or downregulated during the process of adapting hypoxia condition (Gracey et al., 2001; Terova et al.,
2008; Zhang et al., 2017). The recurrence of even short-term hypoxia can affect the hypoxia response (Rytkönen et al., 2012). During embryogenesis, mRNA levels of CITED1 and CITED2 were significantly increased in blunt snout bream during various stages $(2,8,14,20$, and $26 \mathrm{hpf})$ under hypoxia treatment. Moreover, mRNA levels of both CITED1 and CITED2 were obviously enhanced in the brain and their transcriptional areas are expanded. The transcriptional signal returned to normal levels after $30 \mathrm{~h}$ of recovery. Although no data are available on embryonic hypoxia regulation in other fish species, our results demonstrated that blunt snout bream CITED1 and CITED2 mRNAs are inducible in response to hypoxia during embryogenesis.

Blunt snout bream CITED1 and CITED2 mRNA are ubiquitously transcribed in numerous tissues, as observed in mammals and other teleost fish species (Dunwoodie et al., 1998; Gerstner and Landry, 2007; Ng et al., 2010). The highest transcription of CITED1 mRNA were detected in the gill, spleen, and gonad of blunt snout bream. However, the highest transcription was detected in heart and brain in case of grass carp (Ng et al., 2010). The difference in the expression pattern of CITED1 gene suggests that this gene may have an adaptive expression pattern in different fish species. The lowest transcription of CITED1 and CITED2 mRNA was observed in the muscle of blunt snout bream, similar to that reported in the previous study on CITED1 in grass carp ( $\mathrm{Ng}$ et al., 2009, 2010).

After $4 \mathrm{~h}$ hypoxia treatment, both CITED1 and CITED2 mRNAs levels were significantly downregulated in most of tissues except kidney. This downregulation may account for the negative feedback loop for HIF-1 transactivation, wherein these

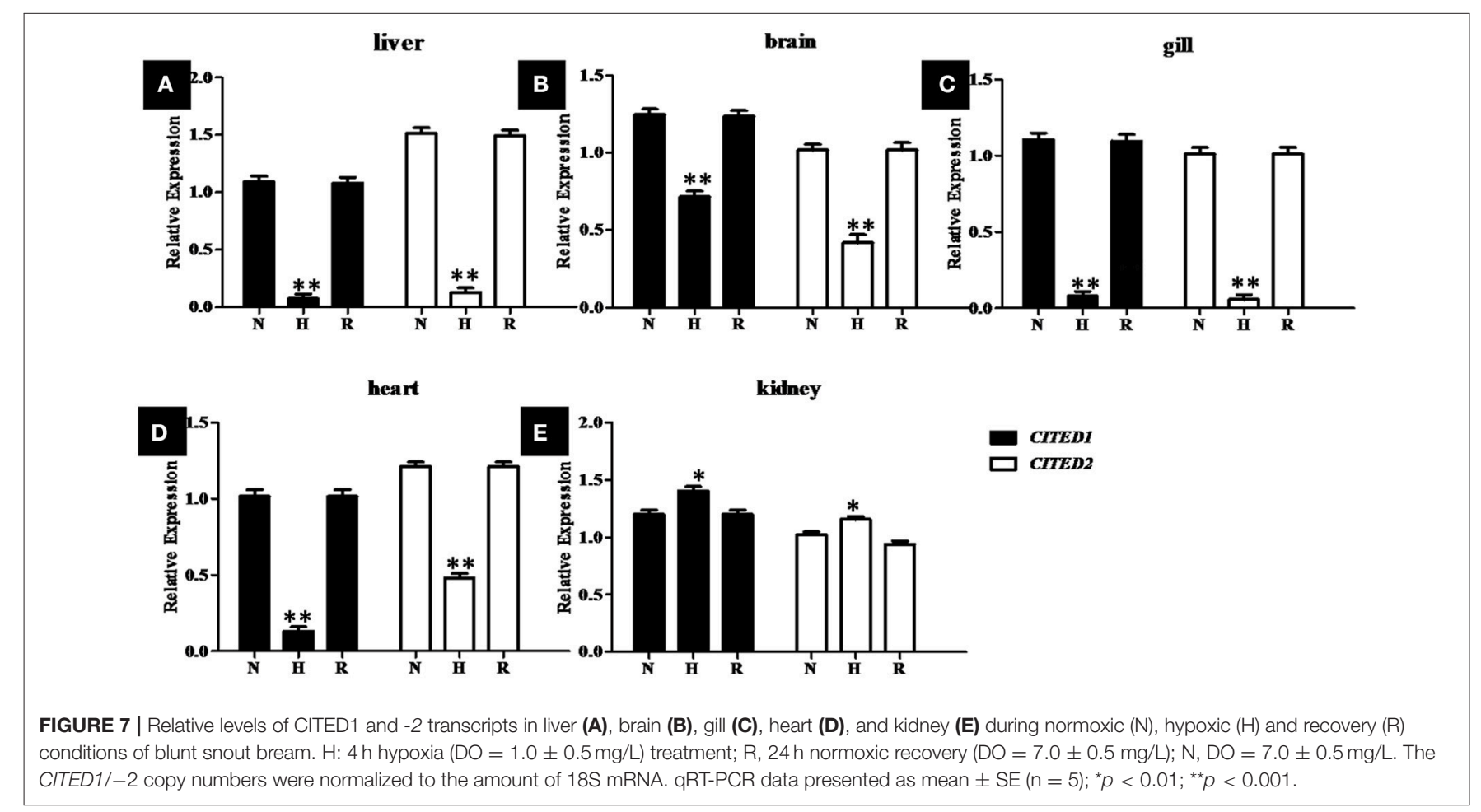


compete for the transcriptional co-activator CBP/p300 (van den Beucken et al., 2007). Under hypoxia conditions, the decrease in the transcription of CITED1 and CITED2 may weaken their capacities to combine with $\mathrm{CBP} / \mathrm{p} 300$. This contributes to the formation of $\mathrm{CBP} / \mathrm{p} 300-\mathrm{HIF}$ complexes that promote the translation of the related downstream genes (van den Beucken et al., 2007). CITED1 mRNA was significantly upregulated in kidney, but its expression was markedly increased in the heart and liver in grass carp ( $\mathrm{Ng}$ et al., 2003, 2009, 2010). These differential regulations in the transcription of CITED1 and CITED2 may contribute to differences in the tolerance to hypoxia between blunt snout bream and grass carp, although further studies are needed to verify this hypothesis.

In conclusion, we successfully characterized the two distinct CITED1 and CITED2 genes in blunt snout bream. Their molecular and spatiotemporal transcriptional patterns and their responses to acute hypoxia suggest that these genes have divergently evolved and may play overlapping biological roles in regulation of response to hypoxia in blunt snout bream. Hypoxic treatment may upregulate CITED1 and CITED2

\section{REFERENCES}

Bamforth, S. D., Bragança, J., Eloranta, J. J., Murdoch, J. N., Marques, F. I., Kranc, K. R., et al. (2001). Cardiac malformations, adrenal agenesis, neural crest defects and exencephaly in mice lacking Cited2, a new Tfap2 co-activator. Nat. Genet. 29, 469-474. doi: 10.1038/ng768

Bhattacharya, S., Michels, C. L., Leung, M. K., Arany, Z. P., Kung, A. L., and Livingston, D. M. (1999). Functional role of p35srj, a novel p300/CBP binding protein, during transactivation by HIF-1. Genes Dev. 13, 64-75. doi: $10.1101 /$ gad.13.1.64

Bracken, C. P., Whitelaw, M. L., and Peet, D. J. (2003). The hypoxia-inducible factors: key transcriptional regulators of hypoxic responses. Cell. Mol. Life Sci. 60, 1376-1393. doi: 10.1007/s00018-003-2370-y

Dunwoodie, S. L., Rodriguez, T. A., and Beddington, R. S. (1998). Msg1 and Mrg1, founding members of a gene family, show distinct patterns of gene expression during mouse embryogenesis. Mech. Dev. 72, 27-40. doi: 10.1016/S0925-4773(98)00011-2

FBMA. (2016). China Fishery Statistical Year Book. Beijing: China Agriculture Press.

Fenner, M. H., Parrish, J. E., Boyd, Y., Reed, V., MacDonald, M., Nelson, D. L., et al. (1998). MSG1 (melanocyte-specific gene 1): mapping to chromosome Xq13. 1, genomic organization, and promoter analysis. Genomics 51, 401-407. doi: 10.1006/geno.1998.5383

Fox, S. B., Bragança, J., Turley, H., Campo, L., Han, C., Gatter, K. C., et al. (2004). CITED4 inhibits hypoxia-activated transcription in cancer cells, and its cytoplasmic location in breast cancer is associated with elevated expression of tumor cell hypoxia-inducible factor lalpha. Cancer Res. 64, 6075-6081. doi: 10.1158/0008-5472.CAN-04-0708

Gerstner, J. R., and Landry, C. F. (2007). Expression of the transcriptional coactivator CITED1 in the adult and developing murine brain. Dev. Neurosci. 29, 203-212. doi: 10.1159/000096389

Giaccia, A. J., Simon, M. C., and Johnson, R. (2004). The biology of hypoxia: the role of oxygen sensing in development, normal function, and disease. Genes Dev. 18, 2183-2194. doi: 10.1101/gad.1243304

Gracey, A. Y., Troll, J. V., and Somero, G. N. (2001). Hypoxia-induced gene expression profiling in the euryoxic fish Gillichthys mirabilis. Proc. Natl. Acad. Sci. U.S.A. 98, 1993-1998. doi: 10.1073/pnas.98.4.1993

Guan, W. Z., Guo, D. D., Sun, Y. W., Chen, J., Jiang, X. Y., and Zou, S. M. (2017). Characterization of duplicated heme oxygenase-1 genes and their responses to hypoxic stress in blunt snout bream (Megalobrama amblycephala). Fish Physiol. Biochem. 43, 641-651. doi: 10.1007/s10695-016-0318-Z transcription in embryos, but decrease their expressions in multiple adult tissues. Our results may provide new insights into the divergence of CITED1 and CITED2 genes and their possible transcriptional or translational regulation in response to hypoxia.

\section{AUTHOR CONTRIBUTIONS}

S-MZ and X-YJ designed experiments; YS and H-HG carried out experiments; YS analyzed experimental results. YS and D-DG analyzed sequencing data and developed analysis tools. YS and S-MZ wrote the manuscript.

\section{ACKNOWLEDGMENTS}

This work was supported by grants from the National Natural Science Foundation of China (31572220), the Key Technologies Research and Development Program of China (2012BAD26B02), and the Shanghai University Knowledge Service Platform (ZF1206).

Jeon, Y. S., Lee, K., Park, S. C., Kim, B. S., Cho, Y. J., Ha, S. M., et al. (2014). EzEditor: a versatile sequence alignment editor for both rRNA- and protein-coding genes. Int. J. Syst. Evol. Microbiol. 64, 689-691. doi: 10.1099/ijs.0.059360-0

Jiang, X. Y., Du, X. D., Tian, Y. M., Shen, R. J., Sun, C. F., and Zou, S. M. (2012). Goldfish transposase Tgf2 presumably from recent horizontal transfer is active. FASEB J. 26, 2743-2752. doi: 10.1096/fj.11-199273

Karim, M. R., Sekine, M., and Ukita, M. (2003). A model of fish preference and mortality under hypoxic water in the coastal environment. Mar. Pollut. Bull. 47, 25-29. doi: 10.1016/S0025-326X(02)00409-5

Kinoshita, K., Kikuchi, Y., Sasakura, Y., Suzuki, M., Fujii-Kuriyama, Y., and Sogawa, K. (2004). Altered DNA binding specificity of Arnt by selection of partner bHLH-PAS proteins. Nucleic Acids Res. 32, 3169-3179. doi: 10.1093/nar/gkh637

Li, F. G., Chen, J., Jiang, X. Y., and Zou, S. M. (2015). Transcriptome analysis of blunt snout bream (Megalobrama amblycephala) reveals putative differential expression genes related to growth and hypoxia. PLoS ONE 10:e0142801. doi: 10.1371/journal.pone.0142801

Livak, K. J., and Schmittgen, T. D. (2001). Analysis of relative gene expression data using real-time quantitative PCR and the 2(-Delta Delta C(T)) Method. Methods 25, 402-408. doi: 10.1006/meth.2001.1262

Martínez, M. L., Raynard, E. L., Rees, B. B., and Chapman, L. J. (2011). Oxygen limitation and tissue metabolic potential of the African fish Barbus neumayeri: roles of native habitat and acclimatization. BMC Ecol. 11:2. doi: 10.1186/1472-6785-11-2

Ng, P. K., Chiu, S. K., Kwong, T. F., Yu, R. M., Wong, M. M., and Kong, R. Y. (2009). Functional characterization of two CITED3 homologs (gcCITED3a and gcCITED3b) in the hypoxia-tolerant grass carp, Ctenopharyngodon idellus. BMC Mol. Biol. 10:101. doi: 10.1186/1471-2199-10-101

Ng, P. K., Wu, R. S., Zhang, Z. P., Mok, H. O., Randall, D. J., and Kong, R. Y. (2003). Molecular cloning and characterization of a hypoxiaresponsive CITED3 cDNA from grass carp. Comp. Biochem. Physiol. B Biochem. Mol. Biol. 136, 163-172. doi: 10.1016/S1096-4959(03) 00224-0

Ng, P. K., Yu, R. M., Kwong, T. F., Wong, M. M., and Kong, R. Y. (2010). Transcriptional regulation and functional implication of the grass carp CITED1 (gcCITED1) in the negative regulation of HIF-1. Int. J. Biochem. Cell Biol. 42, 1544-1552. doi: 10.1016/j.biocel.2010.06.007

Nilsson, G. E., and Ostlund-Nilsson, S. (2004). Hypoxia in paradise: widespread hypoxia tolerance in coral reef fishes. Proc. Biol. Sci. 271(Suppl. 3), S30-S33. doi: $10.1098 / \mathrm{rsbl} .2003 .0087$ 
Ouyang, M., Yu, X., and Chen, D. Y. (2001). The preliminary studies on oxygen consumption rate and asphyxia point of Megalobrama amblycephala in Poyang Lake. J. Jiangxi Fish. Sci. Technol. 4, 20-22. doi: 10.3969/j.issn.1006-3188.2001.04.006

Rytkönen, K. T., Renshaw, G. M., Vainio, P. P., Ashton, K. J., Williams-Pritchard, G., Leder, E. H., et al. (2012). Transcriptional responses to hypoxia are enhanced by recurrent hypoxia (hypoxic preconditioning) in the epaulette shark. Physiol. Genomics. 44, 1090-1097. doi: 10.1152/physiolgenomics.00081.2012

Schlange, T., Andrée, B., Arnold, H., and Brand, T. (2000). Expression analysis of the chicken homologue of CITED2 during early stages of embryonic development. Mech. Dev. 98, 157-160. doi: 10.1016/S0925-4773(00)00454-8

Semenza, G. L. (2001). HIF-1 and mechanisms of hypoxia sensing. Curr. Opin. Cell Biol. 13, 167-171. doi: 10.1016/S0955-0674(00)00194-0

Shen, R. J., Jiang, X. Y., Pu, J. W., and Zou, S. M. (2010). HIF-1alpha and-2alpha genes in a hypoxia-sensitive teleost species Megalobrama amblycephala: cDNA cloning, expression and different responses to hypoxia. Comp. Biochem. Physiol. B Biochem. Mol. Biol. 157, 273-280. doi: 10.1016/j.cbpb.2010.06.013

Shioda, T., Fenner, M. H., and Isselbacher, K. J. (1996). msg1, a novel melanocytespecific gene, encodes a nuclear protein and is associated with pigmentation. Proc. Natl. Acad. Sci. U.S.A. 93, 12298-12303. doi: 10.1073/pnas.93.22.12298

Shioda, T., Fenner, M. H., and Isselbacher, K. J. (1997). MSG1 and its related protein MRG1 share a transcription activating domain. Gene 204, 235-241. doi: 10.1016/S0378-1119(97)00551-9

Tamura, K., Stecher, G., Peterson, D., Filipski, A., and Kumar, S. (2013). MEGA6: molecular evolutionary genetics analysis version 6.0. Mol. Biol. Evol. 30, 2725-2729. doi: 10.1093/molbev/mst197

Taylor, J. S., Braasch, I., Frickey, T., Meyer, A., and Van de Peer, Y. (2003). Genome duplication, a trait shared by 22000 species of ray-finned fish. Genome Res. 13, 382-390. doi: 10.1101/gr.640303

Terova, G., Rimoldi, S., Corà, S., Bernardini, G., Gornati, R., and Saroglia, M. (2008). Acute and chronic hypoxia affects HIF- $1 \alpha$ mRNA levels in sea bass (Dicentrarchus labrax). Aquaculture 279, 150-159. doi: 10.1016/j.aquaculture.2008.03.041

Thisse, B., Heyer, V., Lux, A., Alunni, V., Degrave, A., Seiliez, I., et al. (2004). Spatial and temporal expression of the zebrafish genome by largescale in situ hybridization screening. Methods Cell Biol. 77, 505-519. doi: 10.1016/S0091-679X(04)77027-2

Thompson, J. D., Gibson, T. J., Plewniak, F., Jeanmougin, F., and Higgins, D. G. (1997). The CLUSTAL_X windows interface: flexible strategies for multiple sequence alignment aided by quality analysis tools. Nucleic Acids Res. 25, 4876-4882. doi: 10.1093/nar/25.24.4876

Tian, Y. M., Chen, J., Tao, Y., Jiang, X. Y., and Zou, S. M. (2014). Molecular cloning and function analysis of insulin-like growth factor-binding protein 1a in blunt snout bream (Megalobrama amblycephala). Zool. Res. 35, 300-306. doi: $10.13918 /$ j.issn.2095-8137.2014.4.300 van den Beucken, T., Magagnin, M. G., Savelkouls, K., Lambin, P., Koritzinsky, M., and Wouters, B. G. (2007). Regulation of Cited2 expression provides a functional link between translational and transcriptional responses during hypoxia. Radiother. Oncol. 83, 346-352. doi: 10.1016/j.radonc.2007. 04.026

Wu, C. B., Li, Z. Y., Li, F. G., Chen, J., Jiang, X. Y., and Zou, S. M. (2017). Gill remodeling in response to hypoxia and temperature occurs in the hypoxia sensitive blunt snout bream (Megalobrama amblycephala). Aquaculture 479, 479-486. doi: 10.1016/j.aquaculture.2017.06.020

Yachie, A., Niida, Y., Wada, T., Igarashi, N., Kaneda, H., Toma, T., et al. (1999). Oxidative stress causes enhanced endothelial cell injury in human heme oxygenase-1 deficiency. J. Clin. Invest. 103, 129-135. doi: 10.1172/JCI4165

Yahata, T., Shao, W., Endoh, H., Hur, J., Coser, K. R., Sun, H., et al. (2001). Selective coactivation of estrogen-dependent transcription by CITED1 CBP/p300-binding protein. Genes Dev. 15, 2598-2612. doi: 10.1101/gad. 906301

Yahata, T., Takedatsu, H., Dunwoodie, S. L., Bragança, J., Swingler, T., Withington, S. L., et al. (2002). Cloning of mouse Cited4, a member of the CITED family p300/CBP-binding transcriptional coactivators: induced expression in mammary epithelial cells. Genomics 80, 601-613. doi: 10.1006/geno.20 02.7005

Yoon, H., Lim, J. H., Cho, C. H., Huang, L. E., and Park, J. W. (2011). CITED2 controls the hypoxic signaling by snatching p300 from the two distinct activation domains of HIF-1alpha. Biochim. Biophys. Acta 1813, 2008-2016. doi: 10.1016/j.bbamcr.2011.08.018

Zhang, X. L., Sun, Y. W., Chen, J., Jiang, X. Y., and Zou, S. M. (2017). Gene duplication, conservation and divergence of Heme oxygenase 2 genes in blunt snout bream (Megalobrama amblycephala) and their responses to hypoxia. Gene 610, 133-139. doi: 10.1016/j.gene.2017.02.017

Zhang, Z., Wu, R. S., Mok, H. O., Wang, Y., Poon, W. W., Cheng, S. H., et al. (2003). Isolation, characterization and expression analysis of a hypoxiaresponsive glucose transporter gene from the grass carp, Ctenopharyngodon idellus. Eur. J. Biochem. 270, 3010-3017. doi: 10.1046/j.1432-1033.2003.03678.x

Conflict of Interest Statement: The authors declare that the research was conducted in the absence of any commercial or financial relationships that could be construed as a potential conflict of interest.

Copyright (C) 2018 Sun, Guo, Guo, Jiang and Zou. This is an open-access article distributed under the terms of the Creative Commons Attribution License (CC $B Y)$. The use, distribution or reproduction in other forums is permitted, provided the original author(s) and the copyright owner are credited and that the original publication in this journal is cited, in accordance with accepted academic practice. No use, distribution or reproduction is permitted which does not comply with these terms. 